\title{
Impact of the home-based management of malaria on morbidity and mortality in under-five children in Penka- Michel and Santchou Health Districts of Cameroon
}

\author{
Esther Kenfack Dongmo, Nicholas Tendongfor and Dickson Shey Nsagha* \\ Department of Public Health and Hygiene, Faculty of Health Sciences, University of Buea, P. O. Box 12, Buea,
} Cameroon.

Received 9 November, 2020; Accepted 11 February, 2021

In Cameroon in 2017, malaria accounted for $53 \%$ of hospitalizations, $61 \%$ of deaths among under-five children. The National Program adopted since 2015 the integrated Community Directed Interventions (CDI) for the control of malaria. This study determined the impact of the home-based management of childhood malaria morbidity and mortality in the Penka-Michel and Santchou Health Districts of the West Region in Cameroon. A retrospective hospital record-based study was carried out to assess childhood malaria morbidity and mortality in Penka-Michel where CDI is implemented and in Santchou Health District where CDI is not implemented. Childhood malaria morbidity and mortality were determined from July 2014 to June 2019. The analysis of variance was used to compare the morbidity and mortality before and after CDI. P values of less than 0.05 was considered statistical significant. A total of 32,976 consultations files of children under-five were reviewed. The number of malaria cases increased significantly from $2733(33.7 \%)$ before CDI to $5202(38.4 \%)$ after CDI in the Penka Michel Health District but decreased from 2003 (41.9\%) before CDI to 1723 (40.7\%) after CDI in the Santchou Health District. The number of deaths caused by malaria increased from pre to post CDI in the Santchou Health District from $1(10 \%)$ before CDI to $3(30 \%)$ after CDI but decreased in the Penka Michel Health District from $5(22.7 \%)$ before CDI to $3(13.6 \%)$ after CDI. The implementation of the integrated CDI of malaria in the Penka Michel Health District has benefited the population by enhancing early detection of childhood malaria cases through CHWs in the community; thus significantly increasing morbidity and decreasing mortality.

Key words: Cameroon, children under five, malaria, morbidity, mortality, integrated CDI.

\section{INTRODUCTION}

Malaria is one of the leading causes of childhood morbidity and mortality in Africa (Korenromp et al., 2017;
Amek et al., 2018). About 700,000 to 2.7 million people die of malaria each year, of which more than $75 \%$ are

*Corresponding author. E-mail: nsaghads@hotmail.com. Tel: 00237677499429.

Author(s) agree that this article remain permanently open access under the terms of the Creative Commons Attribution License 4.0 International License 
children (Breman, 2001; Kumar et al., 2007; Ayanlade et al., 2020). In 2017, Cameroon was among the 10 African countries most affected with malaria recording an increase of 131,000 additional cases of malaria compared to the previous year (WHO, 2018). Despite considerable progress in malaria control over the past decade, it remains a major public health problem in Cameroon (Massoda et al., 2018; Ntonifor and Veyufambom, 2016). Malaria was responsible for $53 \%$ of hospitalizations in health facilities in children under five in 2017. It was responsible for $13 \%$ of deaths from all causes, $61 \%$ of these deaths were children under five (MINSANTE Roll Back Malaria, 2018). To increase access to healthcare, the National Program adopted since 2015 the Integrated Community Directed Interventions Strategy, which follows on from home management of malaria (Nkondjio et al., 2019; Sumbele et al., 2020; Nlinwe and Ateh, 2020). Multi-skilled Community Health Workers (CHWs) were trained to take charge in the community of the main killer diseases of children, including malaria, and to strengthen the promotion and prevention of the disease through educational talks and home visits (Roll Back Malaria, 2018).

This program has been implemented through the new financial mechanism of the Global Fund for HIV, Tuberculosis, and Malaria (MINSANTE, 2016). However, the Integrated Community Directed Interventions (CDI) strategy has been implemented only in 85 Health Districts in the 10 Regions of Cameroon with 730 health areas and 4892 community health workers involved (Rashidi, 2017). In the context of the operationalization of this program, priority was given to regions and districts with the lowest health indicators for the three diseases, and with limited access to health facilities (Rashidi, 2017). In the West Region, the strategy was implemented in 5 Health Districts (Bangourain, Foumbot, Kouoptamo, Malantouen, Penka-Michel) with $223 \mathrm{CHWs}$ trained in 55 health areas (Rashidi, 2017).

After one year, 245,796 suspected malaria cases had undergone RDTs, 175,384 confirmed uncomplicated malaria cases received treatment according to the national policy in the community, and 49,255 cases of severe malaria were referred to health facilities in 2017 (Rashidi, 2017). Since the establishment of this program in Cameroon, apart from a mission about the state of progress of the implementation process of the integrated $\mathrm{CDI}$ strategy carried out three months after the setting up of the program to assess the reality on the ground, no evaluation study has been conducted to date (Rashidi, 2017). It is necessary, after two years of implementation of integrated CDI, to evaluate the impact of the mortality and morbidity related to malaria. Thus, a hospital recordbased comparative study of a here/elsewhere type was carried out in two Health Districts to compare childhood malaria mortality and morbidity in a Health District implementing the integrated CDI and a Health District not implementing it. The study aims to determine the impact of the home-based management of childhood malaria morbidity and mortality in Penka-Michel and Santchou Health Districts.

\section{MATERIALS AND METHODS}

\section{Study area}

This study was conducted in the Penka-Michel and Santchou Health Districts of the West Region of Cameroon. The PenkaMichel Health District is one of five Health Districts in the West Region where the integrated CDI is being implemented (Rashidi, 2017). It has 13 health areas with 37 health facilities. Its population is 98,229 inhabitants with a density of 383.7 inhabitants $/ \mathrm{Km}^{2}$ (PenkaMichel Health District Service, 2017). The Santchou Health District is one of the districts in the West Region where the integrated CDI is not implemented and malaria proportional morbidity is high (44.7\%) (Regional Technical Group for Malaria Control, 2018). Santchou Health District has five health areas with 14 health facilities. Its population is 30,376 inhabitants spread over an area of $307 \mathrm{Km}^{2}$ (Santchou Health District Service, 2017).

\section{Study design}

A retrospective hospital record-based study was carried out in Penka-Michel and Santchou Health Districts. Records of health facilities were used to collect the data on childhood malaria morbidity and mortality to evaluate the impact of the malaria management component of the integrated CDI. Thus, malaria morbidity and mortality in children under five were reviewed in the two health districts two and half years before the beginning and two and half years after the beginning of the integrated CDI in the West Region.

\section{Target population}

The target population included all under-five children enrolled in all health facilities in the districts of Penka-Michel and Santchou from July 2014 to June 2019.

\section{Inclusion/exclusion criteria}

The study included all health facilities in the Penka-Michel and Santchou Health Districts that were opened and operating before June 2014. Children under five with incomplete information in the register were excluded.

\section{Sampling methods}

The study adopted a sampling approach, using a probability sampling method to identify the health districts in which we were working. The integrated CDI strategy is being implemented only in 5 Health Districts in the West Region of Cameroon (Bangourain, Foumbot, Penka-Michel Health, Kouoptamo, Malantouen). PenkaMichel Health District has been randomly selected among these five Health Districts. Among the 15 Health Districts where the integrated $\mathrm{CDI}$ is not implemented in the West Region, according to the malaria morbidity report 2018, 4 Health Districts showed high morbidity of malaria (Santchou, Kekem, Galim, Massagam). We 
Table 1. Under-five children reviewed in Santchou and Penka-Michel Health Districts from 2014-2019.

\begin{tabular}{lccc}
\hline Characteristics & Santchou HD & Penka-Michel HD & Total \\
& $\mathbf{N}_{\mathbf{0}}(\%)$ & $\mathbf{N}_{\mathbf{0}}(\%)$ & $\mathbf{N}_{\mathbf{0}}(\%)$ \\
\hline Number of Health Area visited & $5(27.8)$ & $13(72.2)$ & $18(100.0)$ \\
Number of health facilities visited & $10(27.8)$ & $26(72.2)$ & $36(100.0)$ \\
Total number of consultations of children under-five reviewed & $10378(31.5)$ & $22598(68.5)$ & $32976(100.0)$ \\
Proportion of consultations attributed to malaria & $3726(31.9)$ & $7935(68.1)$ & $11661(100.0)$ \\
Total number of childhood malaria death recorded & $10(31.3)$ & $22(68.7)$ & $32(100.0)$ \\
Mortality rate per 1000 & 0.30 & 0.67 & 0.97 \\
\hline
\end{tabular}

therefore randomly selected the Santchou Health District among the 4 .

\section{Data collection procedure}

The data collection form was developed for data extraction and was pre-tested for three health facilities in the Mifi Health District in the West Region of Cameroon. We trained 10 data collectors with a manual using the adult learning method. Trained data collection teams of two persons visited each health facility and collected data for the relevant indicators covering the study period. The review of hospital records was carried out from registers of health facilities in the Penka-Michel and Santchou Health Districts to assess childhood malaria morbidity and mortality. The main sources of data were: (i) outpatient records for the number of children seen in consultation; (ii) inpatient child records for the number of malaria deaths; and (iii) laboratory records for the number of confirmed malaria cases. Administrative authorization was obtained from the Regional Delegate of Public Health and from the District Medical Officers in Penka-Michel and Santchou to access the health facility database. With the assistance of the head of the health facility, trained data collectors identified consultation, hospitalization, and laboratory registers. They went through the records manually and systematically to extract the number of children under five coming for a consultation, number of confirmed malaria cases of children under five, number of all-cause deaths among children under five, and number of deaths due to malaria in children under five from July 2014 to June 2019.

\section{Data management}

All data were checked for accuracy, completeness, and consistency at the end of each day by one of the authors. Hard copies of the data capture sheets were stored in a waterproof box file and electronic databases were kept in password-protected computers. An external hard drive was used to back up the data. Double data entry was done using Epi-data version 3.1.

\section{Data analysis}

All analysis was done using STATA version 13.0 (STATA, College Station, Texas, USA). All continuous variables were summarized using means and standard deviations or medians and inter-quartile ranges, while categorical variables were summarized using proportions or percentages. The analysis of variance test was used to compare the mean morbidity and mortality before and after the integrated CDI. $\mathrm{P}$ values of less than 0.05 was considered statistical significant.

\section{Ethical considerations}

The study was approved by the Institutional Review Board of the Faculty of Health Sciences of the University of Buea (IRB-FHS No: 1023-09). Administrative authorization was obtained from the Regional Delegate of Public Health of the West Region of Cameroon and from the Health Districts Medical Officers of the Penka-Michel and Santchou to access the health facilities database.

\section{RESULTS}

\section{Under-five children reviewed in Santchou and Penka- Michel Health Districts}

Table 1 shows the proportion of health facilities visited and consultation records reviewed for the chart review. Of the 36 health facilities visited, $26(72.2 \%)$ were from Penka-Michel Health District. A total of 32,976 consultations of under-five children either in health facilities or by community health workers (CHWs) were reviewed, of which $10,378(31.5 \%)$ of the consultation reviewed were from the Santchou Health District. Of the 32,976 consultations reviewed, 11,661 (35.4\%) were attributed to malaria. Of the 32 under-five children deaths reviewed in the two Health Districts, 22(68.7\%) was from Penka-Michel Health District. The mortality rate of underfive children in the two health districts was 0.97 per 1000 consultations, of which 0.67 was from Santchou Health District.

\section{Trend of malaria cases in under-five children before and after the CDI period in the Penka and Santchou Health Districts}

The number of malaria cases in under-five children increased steadily from $547(32.1 \%)$ in 2014 to 1354 (48.2\%) in 2019 in the Penka Michel Health District but 


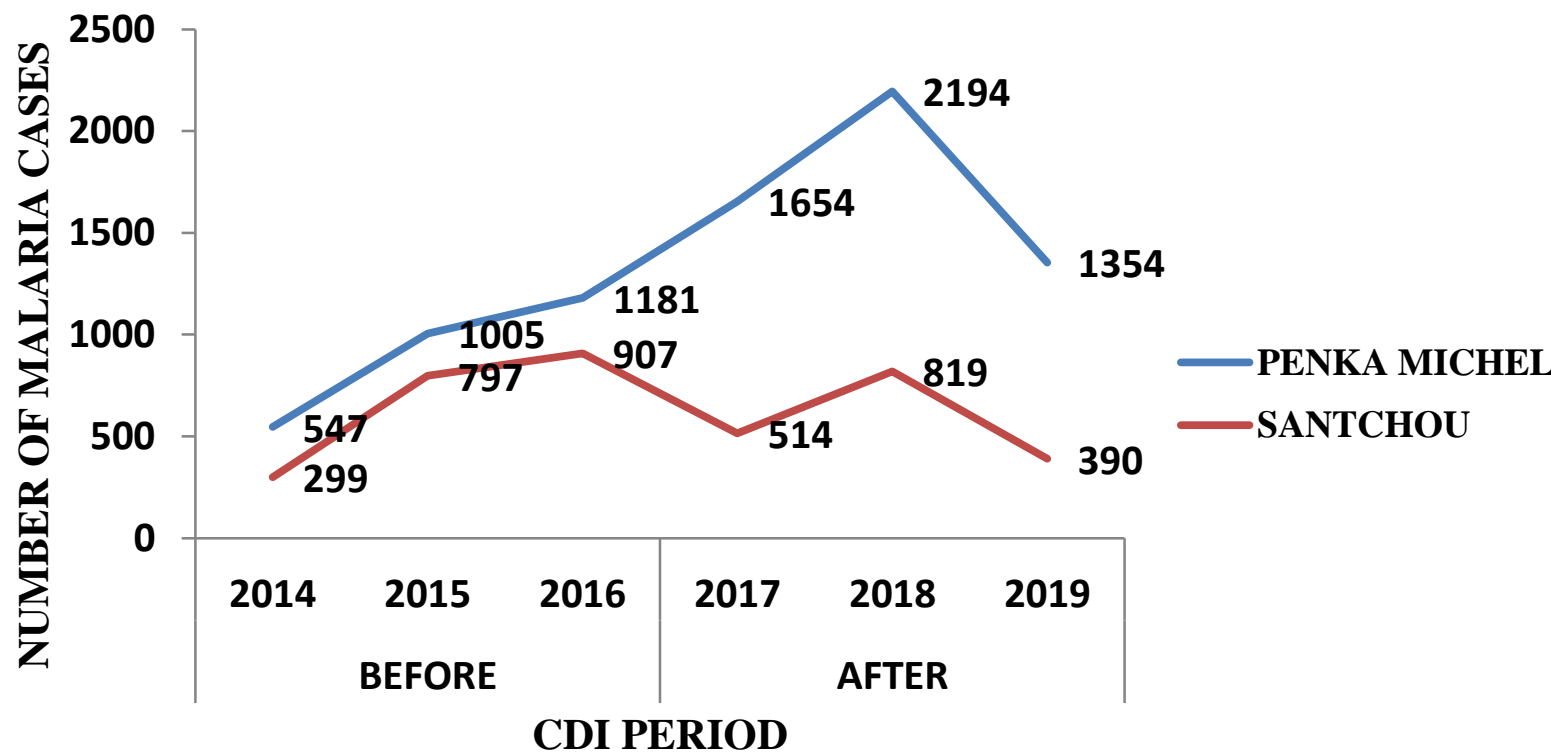

Figure 1. Trend of malaria cases in under-five children before and after the CDI period in the Penka and Santchou Health Districts from 2014-2019.

increased only slightly from 299 (33.9\%) in 2014 to 390 $(35.7 \%)$ in 2019 in the Santchou Health District (Figure 1). The number of malaria cases was relatively higher in the Penka Michel Health District compared to the Santchou Health District across the years.

Trend of malaria death in under-five children before and after the CDI period in the Penka and Santchou Health Districts

The number of deaths due to malaria was relatively higher in the Penka Michel Health District compared to the Santchou Health District. The number of deaths due to malaria increased steadily from $1(0.33 \%)$ to $3(0.77 \%)$ in the Santchou Health District while that of Penka Michel reached up to $5(0.96 \%)$ in 2017 but decreased to 3 $(0.22 \%)$ in 2019 (Figure 2).

Seasonal variation in the morbidity due to malaria in under-five children before and after the integrated CDI in the Santchou and Penka Michel Health Districts

The mean morbidity was generally higher in the Santchou Health District compared to the Penka Michel Health District across the months (January to December). The mean morbidity in Santchou Health District did not show any significant $(F=1.532, p=0.142)$ seasonal variation. Morbidity showed a significant $(\mathrm{F}=4.235, \mathrm{p}=0.001)$ seasonal variation in the Penka Michel Health District. Morbidity was significantly higher in May (45.2\%), June (44.1\%), July (45.3), and August (42.8\%) compared to the other months in the Penka Michel Health District (Figure 3).

Seasonal variation in the mean mortality due to malaria in under-five children before and after the Integrated CDI in the Santchou and Penka Michel Health Districts

The mortality in Santchou Health District did not show any significant $(F=0.954, p=0.442)$ seasonal variation though there was a peak in February (6.9 deaths per 1000 consultation). Mortality did not show any significant $(\mathrm{F}=1.145, \quad \mathrm{p}=0.312)$ seasonal variation in the Penka Michel Health District. The mortality peaked in August (4.8 deaths per 1000 consultation) in the Penka Michel Health District (Figure 4).

Malaria cases in under-five children before and after CDI in the Penka Michel and Santchou Health Districts

The number of malaria cases in under-five children increased significantly from 2733 (33.7\%) before CDI to $5202(38.4 \%)$ after CDI in the Penka Michel Health District but decreased from 2003 (41.9\%) before CDI to $1723(40.7 \%)$ after CDI in the Santchou Health District 


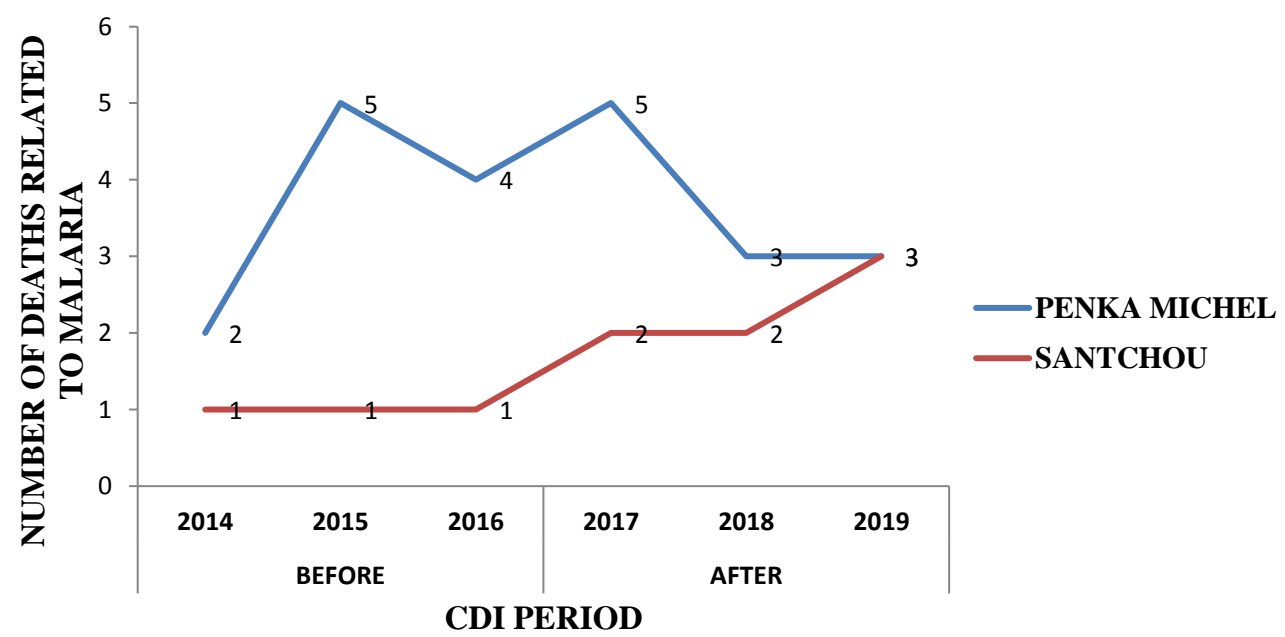

Figure 2. Trend of malaria death in under-five children before and after the CDI period in the Penka and Santchou Health Districts from 2014-2019.

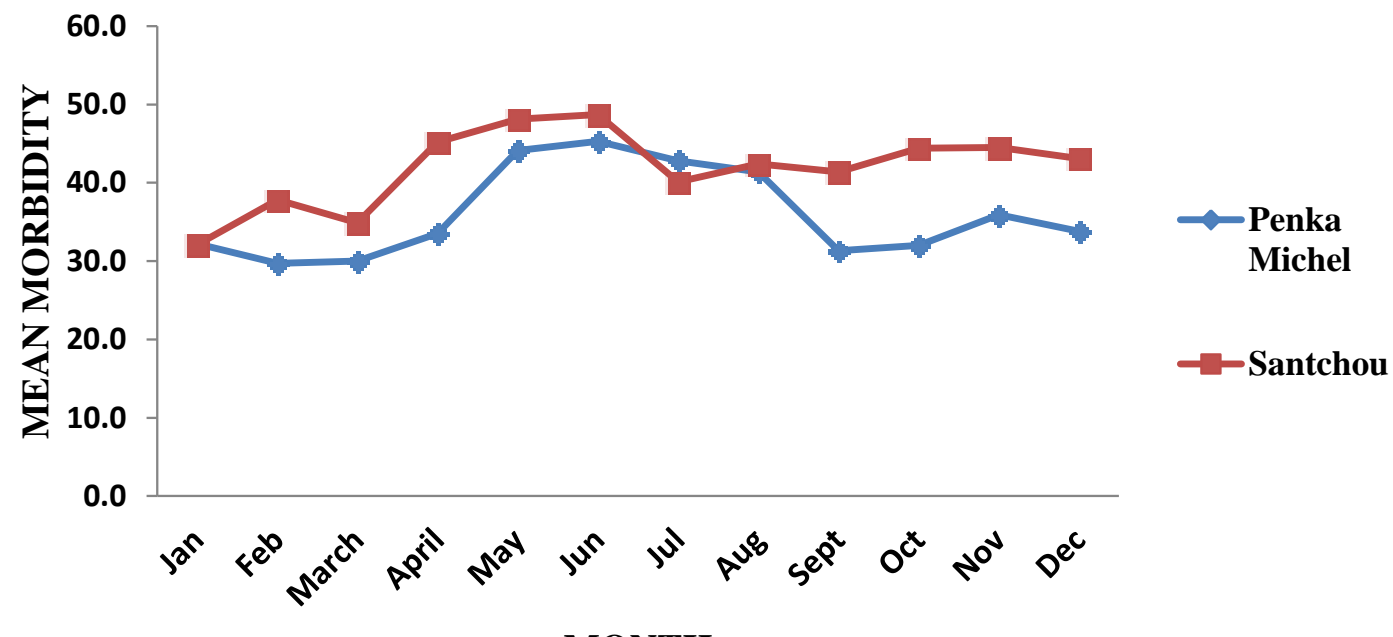

MONTH

Figure 3. Seasonal variation in the mean morbidity due to malaria in under-five children before and after the Integrated CDI in the Santchou and Penka Michel Health Districts from 2014-2019.

(Figure 5).

\section{Deaths due to malaria in under-five children before and after $\mathrm{CDI}$ in the Penka Michel and Santchou Health Districts}

The number of deaths in under-five children caused by malaria increased from 3 (0.1 per 1000) before CDI to 7 (0.3 per 1000) after CDI in the Santchou Health District but remained constant 11 (1.8 per 1000) before and after CDI in the Penka Michel Health District (Figure 6).

\section{DISCUSSION}

This study has investigated the impact of the integrated CDI of childhood malaria morbidity and mortality in Penka Michel and Santchou Health Districts of the West Region of Cameroon. This is such that even though these two health districts sites have different transmission intensities due to their different altitude and topography, it is expected that the impact of the integrated CDI on malaria morbidity and mortality will drop. However, the result of this study shows that the different sites have responded to the Integrated CDI differently. 


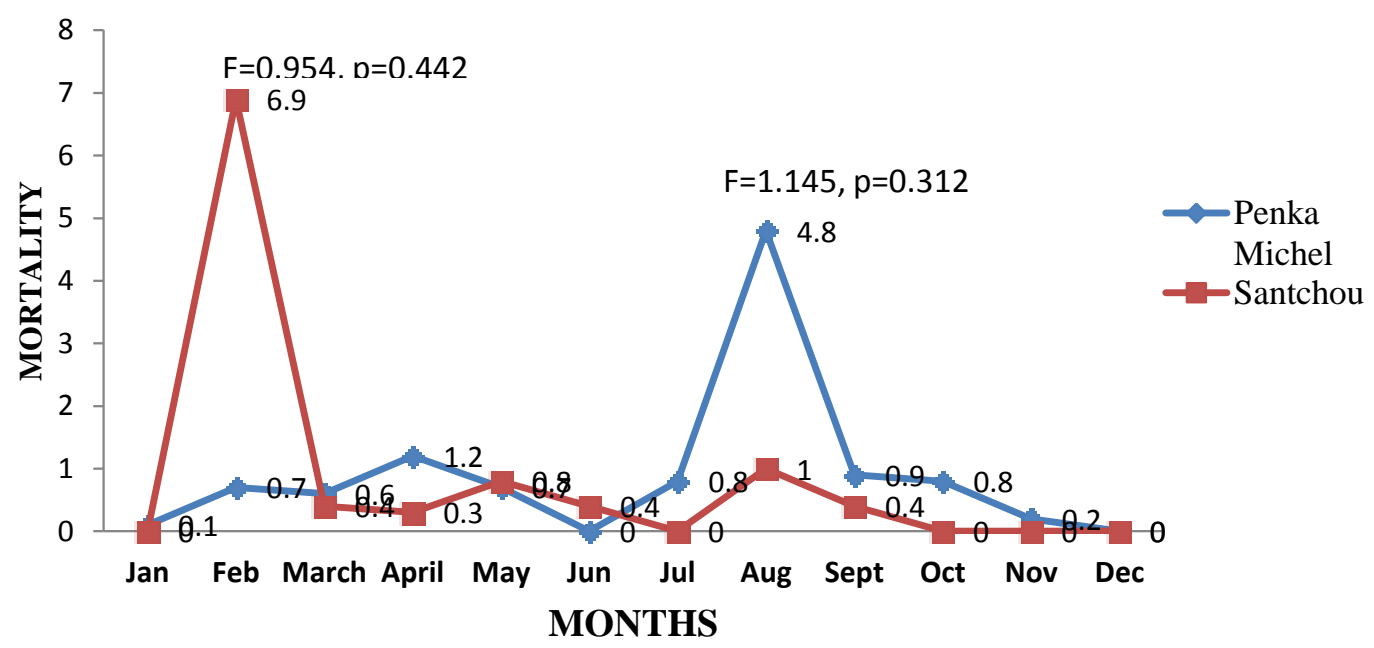

Figure 4. Seasonal variation in the mean mortality due to malaria in under-five children before and after the Integrated CDI in the Santchou and Penka Michel Health Districts from 2014-2019.

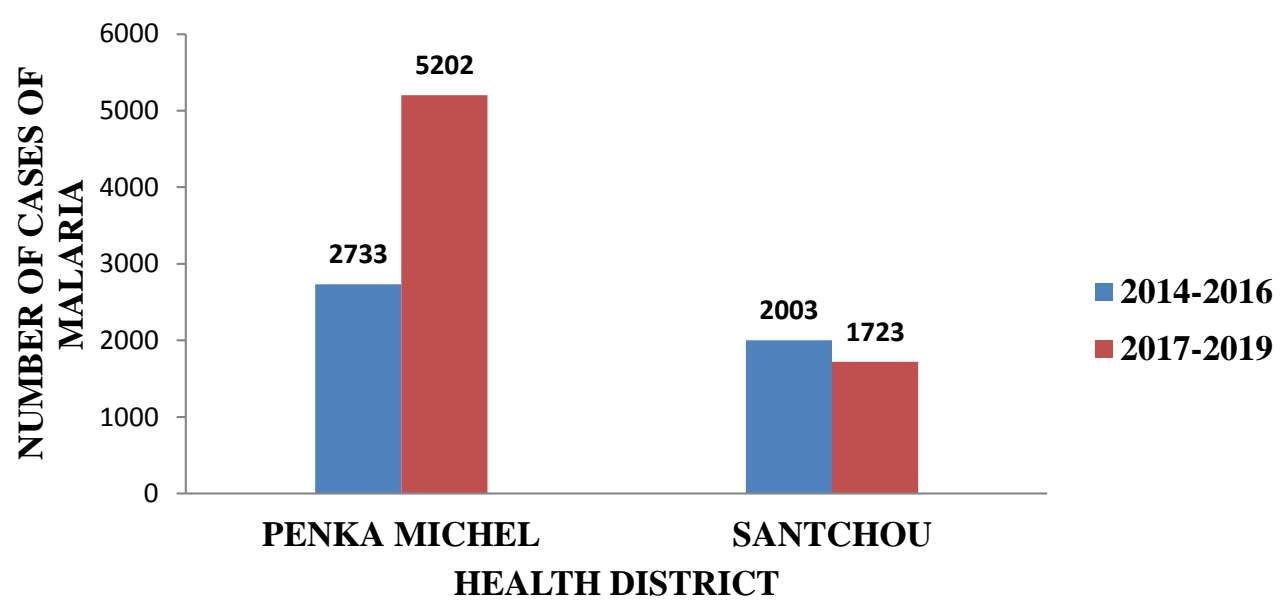

Figure 5. Malaria cases in under-five children before and after CDI in the Penka Michel and Santchou Health Districts from 2014-2019.

\section{Malaria cases in under-five children before and after the CDI period in the Penka-Michel and Santchou Health Districts}

The number of malaria cases in under-five children increased significantly from $33.7 \%$ before CDI to $38.4 \%$ after CDI in the Penka-Michel Health District. This result concurs with that of Fonyuy et al. (2019), who established that the implementation of CDI leads to higher morbidity of childhood malaria. This result is different from that of Ndong et al. (2014) where it was observed that, a declining trend in morbidity was due to changes in malaria treatment. This difference is probably because, under the Integrated CDI of malaria program, there is an increasing trend in malaria morbidity due to an increase in the number of RDTs carried out by the CHWs in the community to determine the positives cases in Penka Michel Health District.

Malaria death in under-five children before and after the CDI period in the Penka and Santchou Health Districts

The number of deaths in under-five children due to malaria increased steadily in the Santchou Health District while that in the Penka Michel Health District decrease after 2017. This is probably since the Integrated CDI had 


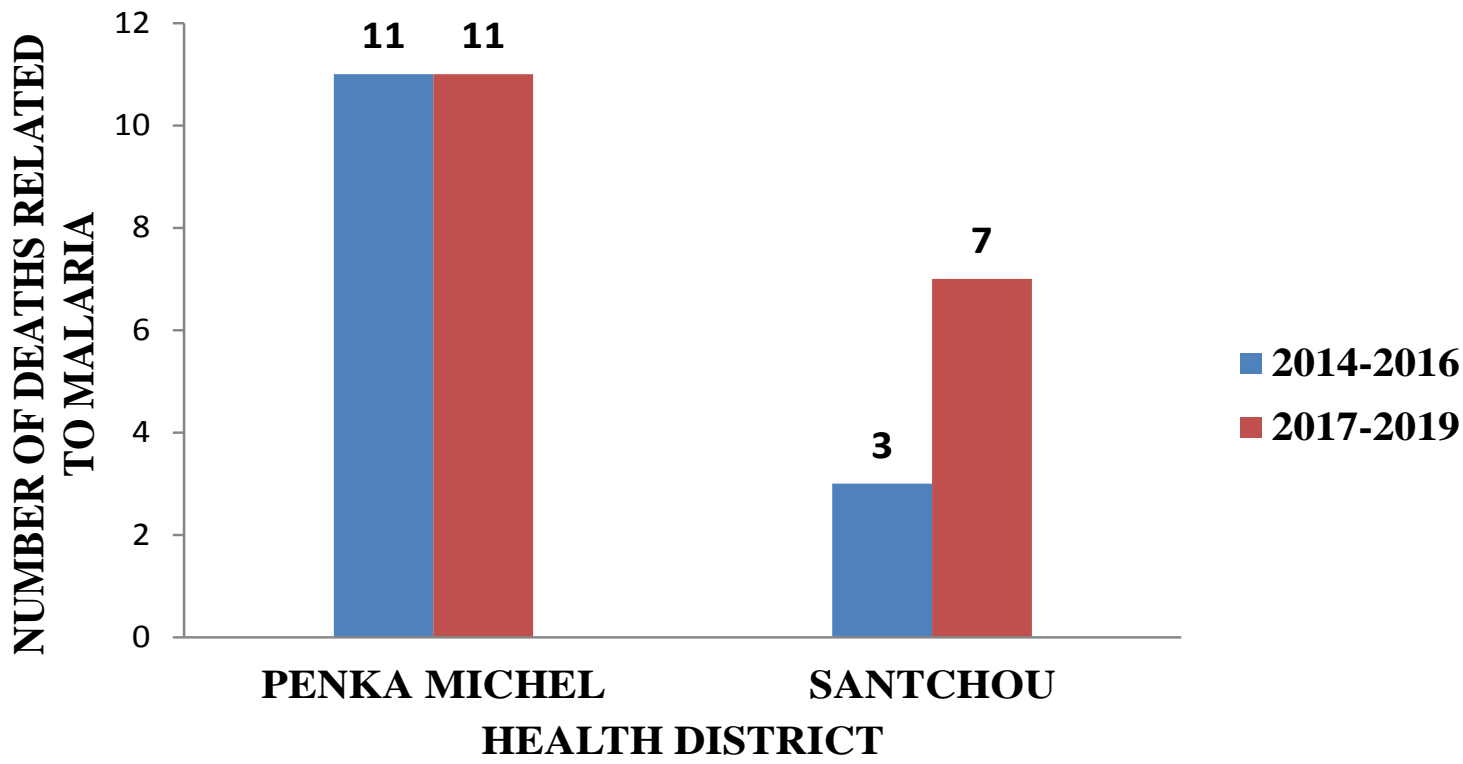

Figure 6. Deaths due to malaria in under-five children before and after CDI in the Penka Michel and Santchou Health Districts from 2014-2019.

been earlier implemented in the Penka Michel Health District and contributed to reducing the mortality rate. This result concurs with that of Eckert et al. (2017) where malaria control interventions substantially contributed to the observed decline in under-five mortality in Rwanda. The mortality rate was low in this study and could be explained by the fact that the surveys were only conducted in health facilities, as some of the children will probably have died at home or upon arrival at the hospital.

Seasonal variation in the morbidity due to malaria in under-five children before and after the Integrated CDI in the Santchou and Penka Michel Health Districts

Morbidity was significantly higher in May, June, July, and August compared to the other months in the Penka Michel Health District. This result concurs with that of (Chiabi et al. 2020; Atangana et al. 2009; Nkuo-Akenji et al. 2006) where the highest transmission rate in Cameroon was during the rainy season.

Seasonal variation in the mean mortality due to malaria in under-five children before and after the Integrated CDI in the Santchou and Penka Michel Health Districts

Mortality in under-five children in the Santchou health district peaked in February; Santchou Health District is located in a marshy area, with many stable water points that can favor the proliferation of mosquitoes. This may explain the peak in childhood mortality in February. Mortality peaked in August in Penka-Michel Health District. This is probably because the highest malaria transmission rates are usually recorded during the rainy season.

\section{Conclusion}

Malaria remains the major cause of consultation for children under-five. The implementation of the integrated CDI of malaria in the Penka Michel Health District of the West Region of Cameroon has benefited the population by enhancing early detection of childhood malaria cases through $\mathrm{CHWs}$ in the community; thus significantly increasing morbidity and decreasing mortality.

\section{Limitation}

A limitation for the current study could be the collection of routine data recorded by the health facilities. Children who died outside of the facilities could not have been captured. However, a general picture of the deaths due to malaria among the under-five children was captured.

\section{CONFLICT OF INTERESTS}

The authors have not declared any conflict of interests. 


\section{ACKNOWLEDGMENTS}

This is part of a Ph.D. thesis by Esther Kenfack Dongmo under the supervision of Professor Nsagha Dickson Shey and Professor Nicholas Tendongfor in the Department of Public Health and Hygiene of the University of Buea. The authors appreciate all stakeholders including the District Medical Officer of Penka-Michel and Santchou Health Districts, Regional Delegate for Public Health of West Region, all Chiefs of health facilities of Penka-Michel and Santchou health districts, data collectors who were instrumental in the realization of this study.

\section{ABBREVIATIONS}

CDI, Community Directed Interventions; CHW, Community Health Worker; HD, Health District; WHO, World Health Organization.

\section{REFERENCES}

Amek NO, Eijk VA, Lindblade KA, Hamel M, Bayoh N, Gimnig J, Laserson KF, Slutsker L, Smith T, Vounatsou P (2018). Infant and child mortality in relation to malaria transmission in KEMRI/CDC HDSS, Western Kenya: validation of verbal autopsy. Malaria Journal 17(37). https://doi.org/10.1186/s12936-018-2184-x

Atangana J, Fondjo E, Fomena A, Tamesse LJ, Patchoké S, Ndjemaï $\mathrm{MNH}$, Ndong BAP (2009) Seasonal variations of malaria transmission in Western Cameroon highlands: Entomological, parasitological and clinical investigations. Academic Journal 3(3):033038. https://doi.org/10.5897/JCAB.9000131

Ayanlade A, Nwayor IJ, Sergi C, Ayanlade OS, Carlo PD, Jeje OD, Jegede MO (2020). Early warning climate indices for malaria and meningitis in tropical ecological zones. Scientific Reports 10(1):113. https://doi.org/10.1038/s41598-020-71094-8

Breman J (2001). The ears of the hippopotamus: manifestations, determinants, and estimates of the malaria burden. American Journal of Tropical Medicine and Hygiene 64(1):1-11. https://www.ncbi.nlm.nih.gov/pubmed/11425172

Chiabi A, Djimafo NMA, Nguefack S, Mah E, Dongmo NF, AngwafollI $F$ (2020). Severe malaria in Cameroon: Pattern of disease in children at the Yaounde Gynaeco-Obstetric and Pediatric hospital. Journal of Infection and Public Health 13(10):1469-1472. https://doi:10.1016/j.jiph.2020.02.038

Eckert E, Florey LS, Tongren JE, Salgado SR, Rukundo A, Habimana JP, Hakizimana E, Munguti K, Umulisa N, Mulindahabi M, Karema C (2017). Impact Evaluation of Malaria Control Interventions on Morbidity and All-Cause Child Mortality in Rwanda, 2000-2010. American Journal of Tropical Medicine and Hygiene 97(3):99-110 https://doi.org/10.4269/ajtmh.17-0281

Fonyuy BE, Sirri MSC, Mercy MK, Ndifor DB (2019). Effectiveness of Community-Directed Intervention in the Roll-Back Malaria among the Under-Five Population of the Ndop Health District in North West Cameroon. Annals of Clinical and Laboratory Research 7(1): 277. https://www.who.int/malaria/publications/world-malaria-report2018/en/

Korenromp E, Hamilton M, Sanders R, Mahiané G, Briët OJT, Smith T, Winfrey W, Walker N, Stover J (2017). Impact of malaria interventions on child mortality in endemic African settings: comparison and alignment between LiST and Spectrum-Malaria model. Public Health 17(4):29-42. https://doi.org/10.1186/s12889017-4739-0
Kumar A, Valecha N, Jain T, Dash AP (2007). Burden of Malaria in India: Retrospective and Prospective View. In: Breman JG, Alilio MS, White NJ, editors. Defining and Defeating the Intolerable Burden of Malaria III: Progress and Perspectives: Supplement to 77(6) American Journal of Tropical Medicine and Hygiene. Northbrook (IL): American Society of Tropical Medicine and Hygiene; Available from: https://www.ncbi.nlm.nih.gov/books/NBK1720/

Massoda Tonye, SG Kouambeng C, Wounang R, Vounatsou P (2018). Challenges of DHS and MIS to capture the entire pattern of malaria parasite risk and intervention effects in countries with different ecological zones: the case of Cameroon. Malaria Journal 17:156. https://doi.org/10.1186/s12936-018-2284-7

MINSANTE (2016). Integrated strategy for the implementation of Community Directed Interventions activities in Cameroon.

MINSANTE, Roll Back Malaria (2018). 2017 activity report of the National Malaria Control Programme.

Ndong IC, van Reenen M, Boakye DA, Mbacham WF, Grobler AF (2014). Trends in malaria admissions at the Mbakong Health Centre of the North West Region of Cameroon: a retrospective study. Malaria Journal 13(1):1-12. https://doi.org/10.1186/1475-287513-328

Nkondjio CA, Ndo C, Njiokou F, Bigoga JD, Awono-Ambene P, Etang J, Ekobo AS, Wondji CS (2019) Review of malaria situation in Cameroon: technical viewpoint on challenges and prospects for disease elimination. Parasites and Vectors 12(1):1-23. https://doi.org/10.1186/s13071-019-3753-8

Nkuo-Akenji T, Ntonifor NN, Ndukum MB, Kimbi HK, Abongwa EL, Nkwescheu A, Anong DN, Songmbe M, Boyo MG, Ndamukong KN, Titanji VPK (2006) Environmental factors affecting malaria parasite prevalence in rural Bolifamba, South West Cameroon. African Journal of Health Sciences 13:40-46

Nlinwe NO, Ateh TAE (2020). Assessment of Malaria Predisposing Factors among Crop Production Farmers Attending the Ndop District Hospital, Northwest Region of Cameroon. Journal of Parasitology Research. https://doi.org/10.1155/2020/1980709

Ntonifor NH, Veyufambom S (2016). Assessing the effective use of mosquito nets in the prevention of malaria in some parts of Mezam Division, Northwest Region Cameroon. Malaria Journal 15(1):390.

Penka-Michel Health District Service (2017). Annual work plan of Penka-Michel Health District.

Rashidi A (2017). Processus d'amélioration de la mise en œuvre de la stratégie intégrée des interventions sous directives communautaires au Cameroun. MINSANTE.

Regional Technical Group for Malaria Control (2018). Annual Report of the West Region of Cameroon.

Santchou Health District Service (2017). Annual work plan of Santchou Health District.

Sumbele IUN, Asoba GN, Teh RN, Metuge S, Anchang-Kimbi JK, Nkuo-Akenji T (2020). Burden of moderate to severe anaemia and severe stunting in children $<3$ years in conflict-hit Mount Cameroon: a community based descriptive cross-sectional study. BMC Pediatrics 20(1):396.

World Health Organization (WHO) (2018). World malaria report. https://www.mmv.org/newsroom/publications/world-malaria-report2018?gclid=Cj0KCQiA4feBBhC9ARIsABp_nbUHkLdZKaSavo_bo4X BeU0EdAmweOvIBzuz7JYpAzXzsB0KdQGzb98aAoX3EALw_wcB 